\title{
CONTRIBUIÇÕES DA HABILIDADE DE ATENÇÃO CONJUNTA PARA A COGNIÇÃO SOCIAL INFANTIL
}

\author{
Fabíola de Sousa Braz Aquino* \\ Nádia Maria Ribeiro Salomão\#
}

\begin{abstract}
RESUMO. O objetivo desse artigo é demonstrar a importância da habilidade da atenção conjunta e suas repercussões na cognição social e na aquisição da linguagem. Defende-se especificamente a ideia de que, no primeiro ano de vida, os bebês desenvolvem, através de atividades compartilhadas e da inserção na cultura, uma forma de comunicação intencional, alicerçada nas primeiras trocas intersubjetivas estabelecidas com adultos. Os debates em torno dessa temática recaem em pontos de vista divergentes. Discute-se, nesse aspecto, qual seria o marco evolutivo a partir do qual a criança se tornaria capaz de estabelecer períodos de atenção conjunta, bem como o momento em que tal habilidade estaria consolidada. Ressalta-se a necessidade de estudos que investiguem a atenção conjunta no primeiro ano de vida da criança, objetivando uma maior compreensão dessa habilidade, dadas as suas implicações no desenvolvimento comunicativo e da linguagem.
\end{abstract}

Palavras-chave: Interação mãe-bebê; atenção conjunta; cognição social.

\section{CONTRIBUTIONS OF THE JOINT ATTENTION ABILITY TO THE INFANT SOCIAL COGNITION}

\begin{abstract}
This article aims to discuss the relevance of joint attention skills and its contribution to social cognition and language acquisition. Also, it defends mainly the idea that in the first year of life babies develops, thought joint attention and cultural insertion, a kind of intentional communication based on the first intersubjective interactions with adults. The discussion about this thematic includes divergent points of view about when the child became able to establish joint attention periods, and the moment in which that skills is consolidated. The importance of studies that investigated joint attention in the first year of life is emphasized in order to have a better understanding of that ability considering its implications to the development of communication and language.
\end{abstract}

Key words: Mother-baby interaction; joint attention; social cognition.

\section{CONTRIBUCIÓN DE LA HABILIDAD DE ATENCIÓN CONJUNTA PARA LA COGNICIÓN SOCIAL INFANTIL}

\begin{abstract}
RESUMEN. En este artículo se discute la importancia de la habilidad de la atención conjunta y sus representaciones en la cognición social y en la adquisición del lenguaje. Plantease precisamente la idea de que en el primer año de vida los niños construyen, a través de actividades compartidas y de la inserción en la cultura, una forma de comunicación intencional, basada en los primeros cambios intersubjetivos establecidos con los adultos. Los debates en torno de esa temática recaen en distintos planteamientos acerca de cuál sería el punto evolutivo en el cual el niño se tornaría capaz de establecer periodos de atención conjunta, y en que momento esta habilidad estaría consolidada. Resaltase la necesidad de estudios que investiguen la atención conjunta en el primero año de vida, objetivando una mayor comprensión de esa habilidad y sus implicaciones en el desarrollo comunicativo y del lenguaje.

Palabras-clave: Interacción madre-niño, atención conjunta, cognición social...
\end{abstract}

Este artigo pretende expor argumentos teóricos acerca da importância de uma habilidade sociocognitiva fundamental para o desenvolvimento da criança e da linguagem, qual seja, a atenção

* Doutoranda em Psicologia Social da Universidade Estadual da Paraíba-UEPB. Professora do Departamento de Psicologia da Universidade Estadual da Paraíba-UEPB.

\# Doutora em Psicologia. Professora do Departamento de Psicologia e do Programa de Pós-Graduação em Psicologia Social da Universidade Federal da Paraíba - UFPB.. 
conjunta. Pesquisadores que investigam essa habilidade (Bruner, 1975, 1980; Baron-Cohen, 1994, 1995; Corkum \& Moore, 1998; Snow, 1999; Tomasello \& Todd, 1983; Tomasello, 1995, 2000, 2003, dentre outros) têm proposto diferentes caminhos - tanto desenvolvimentais quanto metodológicos - para trabalhá-la. Embora os debates em torno dessa temática partam de premissas por vezes antagônicas, há um consenso entre os estudiosos no sentido de que o fenômeno da atenção conjunta é um dos pilares da cognição social e da aquisição da linguagem.

Essa questão é abordada inicialmente a partir da delimitação daquilo que vem sendo entendido por atenção conjunta e cognição social infantil, fenômenos tidos como imbricados no estudo da atenção conjunta. Em seguida, o texto apresenta dados de pesquisas que identificaram relações entre atenção conjunta e os diversos domínios do desenvolvimento infantil e da linguagem, discorrendo ainda sobre teorias clássicas e perspectivas mais recentes de explicação acerca da atenção conjunta. Na parte final do artigo, faz-se referência a pesquisas na área, apresentando-se questionamentos e sugestões para futuros estudos.

\section{ATENÇÃO CONJUNTA: DEFINIÇÕES E CORRELATOS DESENVOLVIMENTAIS}

Antes mesmo de adquirirem a capacidade de se comunicar verbalmente com outros integrantes de sua cultura, os seres humanos transitam em contextos nos quais estão inseridos por meio de ferramentas comunicativas, tais como ações e gestos. Esses instrumentos lhes possibilitam, através da interação social, desenvolver uma interpretação compartilhada de suas atividades conjuntas, através das trocas que se estabelecem com o outro, já no primeiro ano de vida. Vários autores (Cleveland, Schug \& Striano, 2007; D’ Entremont, Hains, \& Muir, 1997; Striano \& Bertin, 2005; Striano \& Vaish, 2006) entendem que, em torno desse mesmo recorte evolutivo, os bebês evidenciam as seguintes habilidades: olhar na direção do olhar do outro; observar a face do outro, quando estão em uma situação ambígua; mostrar e compartilhar objetos com outros. Tais comportamentos destacam-se entre outras ações circunscritas denominadas atenção conjunta.

Estudiosos dessa temática têm verificado uma imbricada relação entre atenção conjunta e cognição social infantil, a qual é investigada a partir de habilidades sociocomunicativas de bebês, desde a mais tenra idade. A cognição social infantil envolve, mais especificamente, a habilidade para compreender outras pessoas, abrangendo o conjunto de capacidades perceptivas que habilita o bebê a discriminar pessoas de objetos. Abrange também o complexo interjogo de pistas sociais, tais como o contato visual, movimentos do corpo, tom de voz e expressões faciais, que auxiliam o bebê na interpretação de comportamentos do outro (Striano \& Reid, 2006). Os rudimentos dessas habilidades podem ser evidenciados em interações face a face mãe-bebê nos primeiros meses e até nos primeiros dias de vida. Elas são consideradas basilares para desenvolver formas mais complexas de habilidades sociocognitivas, tais como interpretar os comportamentos dos outros e utilizar uma comunicação simbólica (Striano \& Bertin, 2005).

Atenção conjunta, por sua vez, tem sido definida como a habilidade de coordenar a atenção entre um parceiro social e um objeto de interesse mútuo. Nesse sentido, envolve a coordenação mútua do adulto e da criança para um foco conjunto num terceiro elemento (Tomasello, 1995). Outros pesquisadores, a exemplo de Butterworth (1995), definiram a atenção conjunta a partir de comportamentos como, por exemplo, seguir o olhar do outro ou olhar na mesma direção para onde alguém está olhando. Autores como Carpenter, Nagell e Tomasello (1998) acrescentaram a essas definições a ideia de que comportamentos como seguir o apontar e o olhar do outro, imitar gestos, iniciar interações e alternar o olhar entre o parceiro e o objeto compartilhado seriam manifestações da compreensão dos outros como seres intencionais.

É importante mencionar que Vygotsky (1984, 2000) já havia destacado a atenção como uma das grandes funções da estrutura psicológica que embasa o uso de instrumentos num contexto social. Segundo ele, a habilidade para focalizar a própria atenção é um determinante essencial do sucesso ou não de qualquer operação prática, pois a criança deve prestar atenção para poder ver. A atenção, auxiliada pela fala, “(...) cria condições para o desenvolvimento de um sistema único que inclui elementos efetivos do passado, presente e futuro. Esse sistema psicológico emergente na criança engloba, agora, duas novas funções: as intenções e as representações simbólicas das ações propositadas" (Vygotsky, 2000, p. 48).

Dunham e Moore (1995) sustentam que os episódios de atenção conjunta são reconhecidos como primordiais para o incremento de um conjunto de dimensões básicas do desenvolvimento cognitivo, social e afetivo. A aquisição dessa habilidade é considerada um dos principais marcos na infância, visto que impulsiona a participação ativa da criança em contextos de aprendizagem sociocultural (Bruner, 1980; Mundy \& Tomasello, 2000). Essa habilidade favorece a comunicação referencial durante as 
interações entre o adulto e o bebê, permitindo o surgimento gradativo de gestos de caráter sociocomunicativo e simbólico, tais como o ato de apontar.

Segundo Bono e Stifter (2003), a atenção conjunta envolve a capacidade de autorregulação do bebê para manter e mudar o foco de atenção, bem como estratégias dos adultos, como a tendência a redirecionar e seguir o foco de atenção dos bebês durante as interações. Em outras palavras, o estabelecimento de contextos de atenção conjunta depende da regulação mútua entre os parceiros e de estratégias sociocomunicativas maternas, tais como modulações vocais, expressões faciais, perguntas, informações sobre aspectos do contexto dirigidas ao bebê, que facilitam o estabelecimento desses episódios.

Mundy, Card e Fox (2000) relataram que as diferenças individuais existentes entre bebês no uso dessa habilidade podem estar associadas a processos corticais frontais. Essas descobertas são consideradas relevantes, na medida em que põem, no contexto das discussões sobre o tema da atenção conjunta, a ideia de que processos de base neurológica podem contribuir para a explicação da tendência das crianças de iniciar episódios de atenção conjunta ou ainda de responder às tentativas dos adultos de redirecionar e manter a atenção conjunta durante as interações com as crianças.

No Brasil, foram desenvolvidos estudos que investigaram a relação entre atenção conjunta e características específicas do input materno (Braz \& Salomão, 2002; Braz Aquino \& Salomão, 2005). Outros estudos observaram diferentes configurações do tempo de atenção conjunta em interações mãe-bebê e mãe-criança, através de uma abordagem transversal (Santos \& Braz Aquino, 2003). Nesses estudos, a atenção conjunta foi delimitada a partir do estabelecimento de um foco compartilhado entre a díade em relação a um terceiro elemento do contexto.

Os resultados extraídos dessas pesquisas corroboraram os dados e premissas de pesquisadores de referência nessa área, como, por exemplo, Tomasello (1995, 1999). Destacam-se, principalmente, aqueles relacionados à ideia de que os episódios de atenção conjunta podem contribuir para o avanço do vocabulário infantil, admitindo-se que há uma variação e aumento do tempo de atenção conjunta estabelecido entre as díades, em função da idade de bebês e crianças. Outros pesquisadores têm discutido o desenvolvimento da habilidade de atenção compartilhada e suas implicações para a identificação precoce de distúrbios invasivos de desenvolvimento como, por exemplo, o autismo (Bosa, 2002, 2004; Lampreia, 2004).

Em torno desta temática, podem ser pontuadas as considerações de Akhtar e Gernsbacher (2007) relativas à importância de se incluir no debate acerca da atenção conjunta a questão das variações culturais que influenciam os tipos de interações nas quais adultos e crianças se engajam. Na concepção desses autores, o estudo da atenção conjunta deve abranger a análise dos contextos reais e frequentemente "polidiádicos" nos quais as díades estão envolvidas, os diferentes estilos de interações mãe-bebê em cada cultura, a influência das crenças e expectativas maternas acerca de como a criança aprende, bem como as diferentes configurações do que tem sido designado de atenção conjunta nos diferentes contextos.

\section{ATENÇÃO CONJUNTA: PERCURSO HISTÓRICO, MODELOS PROPOSTOS E PESQUISAS NA ÁREA}

$\mathrm{Na}$ trajetória das formulações teóricas acerca da atenção conjunta e suas repercussões no desenvolvimento infantil e da linguagem, considera-se fundamental mencionar os pressupostos formulados por Jerome Bruner (1975, 1980), dado o impacto de suas ideias nos modelos e investigações atuais. Bruner (1980) argumentou que o estabelecimento de períodos de atenção conjunta mãe-bebê facilitaria a aprendizagem da linguagem e a solução de problemas pela criança. Isto ocorre quando o adulto cria situações nas quais se evidencia uma correspondência entre o objeto e seu referente linguístico. Tal fato, segundo ele, favoreceria a aquisição de novos vocábulos por parte da criança. De forma geral, os estudos realizados por Bruner nas décadas de 70 e 80 do século XX encontraram correlações positivas entre a quantidade de tempo de atenção conjunta estabelecida entre díades mãe-bebê e o subsequente desenvolvimento do vocabulário infantil.

Em torno desse período, Bakeman e Adamson (1984) realizaram uma pesquisa que corroborou a ideia de que a emergência da habilidade infantil para coordenar a atenção entre um parceiro social e um objeto de interesse mútuo se constitui num marco para o desenvolvimento. Para eles, seria fundamental investigar o surgimento da capacidade de coordenar a atenção por parte das crianças e integrar os campos físico e social, por duas razões: isto auxiliaria no processo de avaliação clínica de crianças com dificuldades no desenvolvimento e ao mesmo tempo tornaria clara a relação entre as principais mudanças 
na estrutura da atenção durante a interação social e o desenvolvimento de habilidades comunicativas específicas.

O impacto da atenção conjunta na cognição social infantil tem sido salientado por Tomasello (1995, 1999, 2000, 2003). Suas investigações pretendem explicar a ontogênese da referida habilidade, as possibilidades de apreensão desse fenômeno e seu papel no desenvolvimento humano. Segundo ele, a maioria dos estudos sobre a atenção conjunta investiga dois aspectos que merecem destaque: 1) a tendência das crianças, antes de completar o primeiro ano de vida, de seguir ou dirigir a atenção visual dos adultos para objetos; e 2) as possíveis ligações entre a habilidade de atenção conjunta e a aquisição de uma "teoria da mente" por parte das crianças.

Nessa perspectiva, surgiram explicações teóricas diversas, dentre as quais pode ser mencionada a apresentada por Butterworth (1995), que defendeu a importância do olhar como um elemento fundamental para a comunicação referencial humana. Nesse sentido, ele realizou estudos norteados pelas seguintes questões: como os bebês sabem para onde o outro está olhando? Qual a relação entre esse comportamento e a compreensão do ato de apontar? De que forma a compreensão do ato de apontar, por parte do bebê, está relacionada à comunicação social? Para responder a essas indagações o referido autor desenvolveu estudos em laboratório sob condições altamente controladas, buscando verificar de que forma os bebês responderiam às mudanças de direção do olhar do adulto para diferentes alvos posicionados numa sala do laboratório.

Os resultados das observações realizadas com bebês entre seis e dezoito meses de idade permitiram ao autor postular a existência de três mecanismos sucessivos de atenção conjunta, especificados e descritos a seguir.

O primeiro mecanismo, designado de "ecológico", utilizaria o olhar da mãe como um sinal orientador, especificando a direção para onde o bebê deveria olhar. Assim, o interesse no objeto integraria a ligação comunicativa com o adulto para especificar a posição para onde o bebê deveria olhar. Isso seria evidenciado em bebês de seis meses, fase em que já demonstrariam a capacidade de usar o olhar dos outros como uma pista para procurar por objetos interessantes.

O segundo mecanismo ocorreria aos doze meses. O bebê exibiria a capacidade de localizar o olhar da mãe e conseguiria fixar intencionalmente o olhar em direção a ela. Essa nova habilidade foi denominada de "mecanismo geométrico", ao estabelecer mais que uma linha invisível entre a mãe e o referente de seu olhar, evidenciando a capacidade do bebê de mapear o caminho para fixar o alvo desejado. Para Butterworth (1995), esse mecanismo diminui a ambiguidade da referência, porque alvos idênticos, mas em posições diferentes, podem ser indicados pelo bebê.

O último mecanismo, denominado de "representacional espacial", evidencia-se quando a criança atinge a idade de dezoito meses. Ele teria como função controlar a atenção visual conjunta, que é baseada na compreensão de que algo está circunscrito no espaço. Esse mecanismo parece se utilizar do movimento do olhar ou da cabeça do adulto e dos sinais de movimento dos olhos. Butterworth (1995) sustenta que, nos primeiros dezoito meses de vida da criança, esses três mecanismos sucessivos estão envolvidos no "olhar para onde alguém está olhando". Trata-se, segundo ele, de uma forma de definir a atenção visual conjunta.

A partir desse estudo, Butterworth (1995) concluiu que bebês, aos seis meses, podem se envolver em uma rede de comunicação, através da compreensão da direção do olhar do adulto. Nessa fase, a direção do olhar do adulto serviria como um indicador geral (esquerda-direita) de para onde o bebê poderia olhar. Para o autor, em geral, a compreensão da habilidade da atenção visual conjunta deve considerar subsistemas motores e atencionais (visão focal e periférica), a atratividade dos estímulos apresentados e o desejo dos bebês de partilhá-los com outros.

Sobre essa temática, também Corkum e Moore $(1995,1998)$ desenvolveram pesquisas com o objetivo de conhecer a natureza da compreensão social infantil nos primeiros dois anos de vida, a idade de emergência da habilidade de atenção conjunta e o caráter inato ou aprendido da atenção conjunta. Esses autores reconhecem a importância da atenção conjunta como um componente central das interações triádicas. Identificam especialmente seu importante papel nas trocas comunicativas durante o período pré-linguístico e a influência desse tipo de fenômeno sociocognitivo em outros comportamentos sociais, percebidos já no final do primeiro ano de vida.

$\mathrm{Na}$ compreensão de Corkum e Moore (1995), diversos aspectos estão relacionados ao estudo da atenção conjunta, destacando-se: as mudanças que ocorrem nesse tipo de comportamento desde sua emergência; a habilidade do bebê em localizar o foco de atenção do outro em situações naturais ou de laboratório; as pistas ou comportamentos do adulto que auxiliam o bebê no estabelecimento da atenção conjunta. Em um estudo de referência na área, 
Corkum e Moore (1995) apontaram evidências de que respostas de atenção conjunta são derivadas de aprendizagem por reforço contingente. Verificaram também o uso, por parte dos bebês, de pistas sociais dadas pelos adultos para estabelecer o foco conjunto e o período de emergência dessa habilidade.

Participaram desse estudo bebês nas idades entre seis e dezenove meses de idade, suas respectivas mães e o experimentador. Os referidos autores utilizaram, pela primeira vez, o paradigma do retorno condicionado da cabeça no estudo da atenção conjunta, no intuito de verificar se essa habilidade poderia ser aprendida por bebês a partir dos seis meses. Os resultados demonstraram que os bebês adquiriram respostas de atenção conjunta após o procedimento de reforço contingente, embora tenham manifestado essa habilidade espontaneamente entre os dez e doze meses de vida, e não antes desse período. Para os autores, esses dados indicam que os bebês aprenderam os comportamentos de atenção conjunta, mas o condicionamento não pareceu ser o elemento necessário e suficiente para a emergência de tal habilidade.

Num estudo posterior, Corkum e Moore (1998) investigaram esses resultados, questionando em que idade e em que condições o comportamento de seguir o olhar do outro seria possível. Participaram desse estudo bebês com idades entre seis e onze meses, os quais foram observados em termos de suas habilidades para usar as pistas dos adultos em relação ao estímulo visual presente numa sala experimental. Os resultados do estudo indicaram que o comportamento de seguir o olhar do adulto por parte dos bebês somente foi observado de forma consistente no final do primeiro ano de vida. Esses mesmos autores encontraram em seus dados uma variabilidade e progressão na idade de emergência do ato de seguir o olhar do outro, levandoos a supor que os bebês devem estar num nível de desenvolvimento apropriado para manifestar esse tipo de comportamento. Além disso, assinalaram que os bebês podem seguir o olhar do outro e compartilhar atenção, mesmo sem uma compreensão dos outros ou de si mesmos.

Partindo de uma perspectiva neurocognitiva, Baron-Cohen $(1994,1995)$ defende a ideia de que a evolução da espécie humana fez surgir um sistema neurocognitivo para a rápida detecção dos olhos de outro organismo, tendo essa habilidade uma considerável função adaptativa. Ele afirma que as formas mais complexas de interação social da espécie humana impulsionaram a sofisticação de seu nível cognitivo e aumentaram, de forma rápida e adaptativa, a inteligência social dos humanos. Segundo acrescenta, num nível biológico, teria ocorrido um aumento de diferentes mecanismos cerebrais que possibilitariam ao ser humano, desde a infância, direcionar seu olhar para um determinado alvo.

Baron-Cohen $(1994,1995)$ propõe a existência de um sistema neurocognitivo ligado à habilidade dos seres humanos para atribuir estados mentais como interpretar e predizer ações de outros. Esse sistema é composto de quatro módulos, quais sejam: um detector de intencionalidade (Intentionality Detector $I D$ ), um detector de direção do olhar (Eye Direction Detector - EDD), um mecanismo de atenção compartilhada (Shared Attention Module - SAM) e um mecanismo de teoria da mente (Theory of Mind Mechanism - ToMM).

Conforme Baron-Cohen (1994), o detector de intencionalidade é um mecanismo perceptivo primitivo que interpreta estímulos em termos de suas metas e desejos e constrói representações diádicas. Num texto posterior (Baron-Cohen,1995), o autor não faz menção ao detector de intencionalidade. Este, na verdade, refere-se diretamente ao detector de direção do olhar como o primeiro mecanismo advindo de uma evolução da espécie humana.

O detector de direção do olhar é capaz de construir representações diádicas através do uso de cálculos geométricos precisos. De acordo com BaronCohen (1995), “(...) sempre que o detector de direção do olhar localiza os olhos de outra pessoa, ele gradualmente forma representações do comportamento do olho" (p. 48). Para ele, isso ocorre quando o bebê está com, no mínimo, quatro meses de idade, ou, até mesmo, antes. Essas representações diádicas evidenciam a presença de duas entidades (agente e eu; ou agente e objeto; ou eu e objeto), colocadas uma em relação à outra. Esse tipo de composição diádica supõe que o organismo tem um conceito sobre "está vendo algo", um conceito de "eu" e um conceito de "ver a si mesmo".

O módulo de atenção compartilhada (Shared Attention Module - SAM) funciona para identificar se o indivíduo e o outro organismo estão atentos ao mesmo objeto. Esse módulo constrói relações triádicas, as quais diferem em sua estrutura das representações diádicas, por incluir um terceiro elemento, especificando que "o sujeito e o eu" estão ambos atentos ao mesmo objeto. Baron-Cohen (1995) explica ainda que “(...) a capacidade para construir representações triádicas é necessária para a atenção conjunta e, em primeira instância, o módulo de atenção compartilhada constrói essas representações usando representações diádicas que ela obteve dos outputs do detector de direção do olhar" (p.50). A 
forma mais evidente do funcionamento do módulo de atenção compartilhada é o olhar monitorado. Ao lado do gesto de apontar, indica comportamentos de atenção visual conjunta.

Finalmente, o quarto módulo, a teoria do mecanismo mental (Theory of Mind Mechanism ToMM), produz um mecanismo para ligar o conhecimento dos estados mentais, compondo um todo coerente. Na ótica de Baron-Cohen (1995), no caso específico dos seres humanos, o mecanismo de atenção compartilhada teria um papel crucial na ontogênese de uma teoria da mente em crianças. $\mathrm{O}$ autor explicita sua compreensão da atenção conjunta com base em dois mecanismos neurocognitivos gerais: o que identifica se o sujeito é o alvo de atenção do outro (representações diádicas) e o que estabelece o foco de atenção compartilhada com outro (representações triádicas).

No outro polo desse debate, podem ser mencionadas as articulações teóricas desenvolvidas por Tomasello $(1995,1999,2000,2003)$ acerca da atenção conjunta. Partindo de uma abordagem sociopragmática, o autor desenvolve uma posição contrária às anteriormente descritas ao propor, em suas explicações, a ideia de que a atenção conjunta e suas reconfigurações nos dois primeiros anos de vida devem ser analisadas como integradas às interações sociais das crianças, suas trocas efetivas com os outros e sua sincronia com o desenvolvimento global.

Para Tomasello (1995), a atenção conjunta é primariamente um fenômeno social ou sociocognitivo que possui uma natureza bastante peculiar. $\mathrm{Na}$ sua concepção, esse tipo de episódio interativo é acompanhado por uma compreensão de que o outro participante da interação tem seu foco de atenção dirigido a um mesmo objeto. Ele defende que o aspecto intencionalmente comunicativo da linguagem é mais do que a cognição ou o desenvolvimento de uma teoria da mente, a característica que diferencia definitivamente a espécie humana das demais.

Em suas teorizações, Tomasello (2003) assinala que, entre os nove e doze meses de idade, os bebês começam a se envolver num conjunto de novos comportamentos que parecem indicar uma "revolução" no modo de entender seu mundo, sobretudo o mundo social. Essa nova forma de interagir com o meio social e com a cultura é evidenciada por comportamentos de atenção conjunta e pela compreensão, por parte dos bebês, das outras pessoas como agentes intencionais iguais a eles, cujas relações com entidades externas podem ser acompanhadas, dirigidas ou compartilhadas.
Tomasello (2003) define cena de atenção conjunta como “(...) interações sociais nas quais a criança e o adulto prestam conjuntamente atenção a uma terceira coisa, e a atenção um do outro à terceira coisa dá-se por um período razoável de tempo" (p.135). O autor introduz a expressão "cena de atenção conjunta" para garantir a ênfase a dois aspectos essenciais, nem sempre ressaltados em discussões anteriores, quais sejam: a) o que está incluído nas cenas de atenção conjunta - um subconjunto de objetos do mundo perceptual da criança que ocupam o meio-termo essencial da realidade socialmente compartilhada entre o mundo perceptual, mais amplo, e o mundo lingüístico, menos extenso; b) a consideração de que a compreensão que a criança tem de uma cena de atenção conjunta inclui como elemento fundamental a própria criança e seu papel na interação, de modo que todos estejam num formato representacional comum.

Mais recentemente, Tomasello, Carpenter, Behne e Moll (2005) apresentaram uma nova forma de pensar a estrutura interativa da atenção conjunta, propondo os seguintes níveis desse construto: a) engajamento diádico (em torno dos seis meses), presente nas interações onde predominariam o compartilhamento de emoções, trocas de turno e comportamentos, caracterizando-se por episódios nos quais um indivíduo interage com outro, sendo mutuamente responsivo a ele; b) engajamento triádico (entre nove e doze meses), presente nas interações em que se observaria o envolvimento do bebê e do adulto com um terceiro elemento para o qual ambos dirigiriam sua atenção e ações; c) engajamento colaborativo (a partir dos doze meses), evidenciado pela mudança qualitativa no tipo de engajamento social e por uma maior compreensão, por parte do bebê, de planos de ações intencionais do parceiro. Logo após esse período, ocorre uma nova aquisição, que configura outro aspecto dessa mudança qualitativa nos tipos de troca estabelecidos: o surgimento da linguagem no sentido de comunicação linguística.

A concepção de Tomasello (1995, 1999, 2003) sobre a habilidade de atenção conjunta e a defesa de uma estreita relação desta com a dimensão sociocomunicativa da linguagem foi resgatada no presente artigo principalmente em razão dos desmembramentos apresentados pelo autor para explicar como o fenômeno da atenção conjunta e a instância intencional da linguagem podem ser úteis na explicação da ontogênese do desenvolvimento humano.

O conjunto de modelos teóricos apresentado e a complexidade desse fenômeno nos levam a pensá-lo como resultante da participação humana em contextos 
culturais que se coloca com uma tendência nos bebês, já no primeiro ano de vida, para se identificar com outros e agir ativamente nos diversos contextos interativos. Além disso, no presente artigo, compartilha-se a premissa de que a atenção conjunta é parte constitutiva e basilar para a aquisição da cultura humana, em virtude de seu caráter intrinsecamente sociocomunicativo e interativo.

Os argumentos apresentados em cada perspectiva descrita são considerados imprescindíveis, visto que têm impulsionado pesquisas buscando promover uma melhor compreensão e explicação da relação entre os contextos interativos nos quais se evidenciavam episódios de atenção conjunta e seu papel na formação da cognição social infantil.

Buscando uma melhor apreensão da habilidade de atenção conjunta e suas relações com aspectos sociocomunicativos da linguagem, Carpenter et al. (1998) realizaram um amplo estudo longitudinal para investigar a emergência e evolução de habilidades sociocognitivas de bebês entre nove e quinze meses de idade. No conjunto de resultados desse estudo, destaca-se a descoberta de uma ordem no surgimento de tais habilidades, qual seja: atenção conjunta (média de 9 meses), gestos comunicativos (média de 10.3 meses), o ato de seguir a atenção (média de 11.5 meses), a aprendizagem imitativa (média de 11.9 meses) e a linguagem referencial (após os 15 meses). Para Carpenter et al. (1998), uma das mais importantes descobertas do estudo foi a identificação de uma forte relação positiva entre a quantidade de tempo que as díades mãe-bebê passavam em episódios de atenção conjunta e muitas das primeiras habilidades de comunicação linguística e não-linguística.

A relevância dessa temática no campo da aquisição da linguagem e da cognição social tem conduzido pesquisadores (Striano \& Vaish, 2006) a investigar que tipos de contextos interativos possibilitariam o estabelecimento de episódios de atenção conjunta entre adulto e bebê (se uma face neutra ou alegre dirigida ao bebê, se atividades ou brinquedos a ele oferecidos). Buscaram também investigar se esses episódios estariam necessariamente vinculados a uma maturação por parte do bebê quanto à habilidade de monitorar e compreender as motivações e metas dos outros, quando interagem com ele.

Em relação a essa última questão, Cleveland, Schug e Striano (2007) encontraram variações nas habilidades de bebês entre cinco e sete meses de idade no que se refere à capacidade de compreender as pistas sociais dos outros e extrair delas informações acerca de um novo objeto e seu referente linguístico.
Uma revisão de estudos feita por esses autores demonstrou que, antes dos cinco meses de vida, os bebês se mostravam sensíveis a uma série de pistas de seus parceiros sociais. Segundo eles, esse comportamento exerceria uma influência na capacidade de processamento de informações do mundo circundante, por parte dos bebês. Esclarecem, por fim, que as pistas sociais proporcionadas pelas interações dos bebês com adultos seriam fundamentais para explicar a aquisição da capacidade de atenção conjunta e de rótulos linguísticos.

Essas pesquisas têm demonstrado a relevância do estudo da atenção conjunta e da magnitude de sua influência no desenvolvimento global infantil. Além disso, o estudo dessa habilidade e sua estreita relação com as primeiras formas simbólico-culturais emergentes em bebês já no primeiro ano de vida permite que pesquisadores da área continuem investigando o papel desse tipo de contexto intersubjetivo na explicação de formas atípicas de comunicação e cognição social.

\section{CONSIDERAÇÕES FINAIS}

O presente artigo pretende contribuir para a discussão e compreensão relativas à habilidade da atenção conjunta, considerada fundamental para a construção da cognição social infantil. Defende-se a premissa de que essa habilidade se desenvolve a partir da intersubjetividade inerente às trocas que se estabelecem entre o adulto e a criança. Tal habilidade se constrói num contexto sociocultural, no qual são essenciais as atividades e ações conjuntamente compartilhadas, consideradas tipicamente humanas. Enfatiza-se, nesse aspecto, o papel do outro social na construção conjunta da esfera sociocomunicativa infantil, sendo esta uma das precursoras das primeiras manifestações de capacidade de comunicação intencional e da linguagem.

Considera-se indispensável o aprofundamento dos estudos nesse campo, tendo-se em vista que permanecem sem conclusões a questão da emergência, a inter-relação e os vários significados das habilidades de atenção conjunta no primeiro ano de vida do bebê e suas relações com a habilidade de comunicação intencional, como ressaltam Striano e Bertin (2005). Autores como Striano e Vaish (2006) afirmam que a possível razão para as controvérsias com relação ao período de emergência da atenção conjunta repousa no fato de estudos de referência nessa área (Carpenter et al.,1998) terem avaliado os bebês após o surgimento dessas habilidades, e não num período anterior, 
quando seria possível identificar seu marco ontogenético.

$\mathrm{Na}$ perspectiva de contribuir com as pesquisas nessa área, este artigo sugere a realização de estudos que explorem as variáveis implicadas na emergência e evidências de habilidades de atenção conjunta, a partir de um olhar crítico sobre as diferentes definições e propostas metodológicas adotadas no estudo da atenção conjunta. Com essa preocupação, questiona-se até que ponto o tempo e a frequência de episódios de atenção conjunta nas interações entre mãe e bebê poderiam ser influenciados pela maturação neurofisiológica da função psicológica "atenção", que permite aos humanos focar por mais tempo um objeto conjuntamente compartilhado; ou se variáveis como estilos comunicativos maternos, responsividade $\mathrm{e}$ concepções maternas sobre as habilidades dos bebês, contextos ou situações criadas durante as interações e características dos próprios bebês durante suas interações, não seriam fatores que se entrecruzariam, propiciando diferentes cenários interativos.

Defende-se também neste estudo que as problematizações em torno da atenção conjunta remontam à noção básica de intersubjetividade e ao papel que exercem as primeiras formas de interação mãe-bebê na construção de um tipo de comunicação e interação mais complexas. Neste sentido, formulam-se os seguintes questionamentos: que explicações podem perpassar a análise do processo de interações mãebebê nos primeiros meses de vida, quando o bebê ainda interage de forma rápida e ambígua? É possível afirmar que o não-estabelecimento de episódios de atenção conjunta seria uma evidência da "assimetria" que prevalece nas primeiras interações mãe-bebê? O estabelecimento de episódios de atenção conjunta seria o principal critério que definiria uma "interação"? Considera-se pertinente que futuras pesquisas analisem essas questões, uma vez que tais aspectos ainda parecem pouco elucidados.

O estudo desse tema, sem dúvida, é profícuo para a compreensão da cognição social infantil e da linguagem. Propicia também o debate referente às novas descobertas em torno das características dessa habilidade em indivíduos com distúrbios específicos na linguagem e na comunicação, como o autismo (Carpenter, Pennigton \& Rogers, 2001; Hill, 2004; Rollins, 1999), e em crianças cegas, cuja habilidade para focar conjuntamente um determinado evento estaria inicialmente prejudicada (Akhtar \& Gernsbacher, 2007).

Por essas e outras razões, defende-se a necessidade de se realizar um estudo minucioso das estruturas interativas que englobam a atenção conjunta. A partir da análise do conjunto de teorizações em torno da aquisição da linguagem, pode-se evidenciar a importância do estudo da ontogênese da comunicação e de habilidades prélinguísticas, consideradas fundamentais para o desenvolvimento sociocognitivo infantil, sob uma perspectiva sociocomunicativa.

\section{REFERÊNCIAS}

Akhtar, N., \& Gernsbacher, A (2007). Joint attention and vocabulary development: a critical look. Language and Linguistic Compass, 1(3), 195-207.

Bakeman, R., \& Adamson, L. B. (1984). Coordinating attention to people and objects in mother-infant and peer-infant interaction. Child Development, 55, 1278-1289.

Baron-Cohen, S. (1994). How to build a baby that can read minds: cognitive mechanisms in mindreading. $C P C, 13(5), 513-552$.

Baron-Cohen, S. (1995). The eye direction detector (EDD) and the shared attention mechanism (SAM): Two cases for evolutionary psychology. In C. Moore \& P. J. Dunham (Eds.), Joint attention: its origins and role in development (pp.41-59). Hillsdale, NJ: Lawrence Erlbaum Associates.

Bono, M. A., \& Stifter, C. A . (2003). Maternal attention-directing strategies and infant focused attention during problem solving. Infancy, 4(2), 235-250.

Bosa, C. A. (2002). Atenção compartilhada e identificação precoce do autismo. Psicologia: Reflexão e Crítica, 15(1), 77-88.

Bosa, C. A. (2004). Autismo: intervenções psicoducativas. Revista Brasileira de Psiquiatria, 28(1), 47-53.

Braz, F. de S., \& Salomão, N. M. R. (2002). Episódios de atenção conjunta em contextos de brincadeira livre. Interações, 14, VII, 85-104.

Braz Aquino, F. de S., \& Salomão, N. M. (2005). Estilos diretivos maternos apresentados a meninos e meninas. Estudos de Psicologia, (002), 10, 223-230.

Bruner, J. S. (1975). From communication to language: a psychological perspective. Cognition, 3(3), 255-287.

Bruner, J. S. (1980). Early social interaction and language acquisition. In H. R. Schaffer (Ed.), Studies in mother-infant interaction (pp. 271-289). New York: Academic Press Inc.

Butterworth, G. (1995). Origins of mind in perception and action. In C. Moore \& P. J. Dunham (Eds.), Joint attention: Its origins and role in development (pp. 29-40). Hillsdale, NJ: Lawrence Erlbaum Associates.

Carpenter, M., Nagell, K., \& Tomasello, M. (1998). Social cognition, joint attention, and communicative competence from 9 to 15 months of age. Monographs of the society for research in child development, 63(4), 1-175.

Carpenter, M.; Pennington, B. F., \& Rogers, S. J. (2001). Understanding of others' intentions in children with autism. Journal of autism and development disorders, 31(6), 589-599.

Cleveland, A., Schug, M., \& Striano, T. (2007). Joint attention and object learning in 5-and7-month-old infants. Infant Behavior \& Development, 29(3), 299-307. 
Corkum, V., \& Moore, C. (1995). Development of joint visual attention in infants. In C. Moore \& P. J. Dunham (Eds.), Joint attention: Its origins and role in development (pp. 61-83). Hillsdale, N J: Lawrence Erlbaum Associates.

Corkum, V., \& Moore, C. (1998). The origins of joint visual attention in infants. Developmental psychology, 34(1), 28-38.

D’ Entremont, B., Hains, S. M. J., \& Muir, D. W. (1997). A demonstration of gaze following in 3- to 6 - month-olds. Infant Behavior and Development, 20(4), 569-572.

Dunham, P. J., \& Moore, C. (1995). Current themes in research on joint attention. In: C. Moore \& P. J. Dunham (Eds.), Joint attention: Its origins and role in development (pp. 15-28). Hillsdale, NJ: Lawrene Erlbaum Associates.

Hill, E. L. (2004). Executive dysfunction in autism. Trends in Cognitive Sciences, 8(1), 26-32.

Lampreia, C. (2004). Os enfoques cognitivista e desenvolvimentista no autismo: uma análise preliminar. Psicologia: Reflexão $e$ Crítica, 17(1), 111-120.

Mundy, P., Card, J., \& Fox, N. (2000). EEG Correlates of the development of infant joint attention skills. Development Psychobiology, 36, 325-338.

Rollins, P. R. (1999). Early pragmatic accomplishments and vocabulary development in preschool children with autism. American Journal of Speech-language Pathology, 8, 181-190.

Santos, R. M., \& Braz Aquino, F. de S. (2003). Episódios de atenção conjunta num contexto de brinquedo livre: um estudo transversal [Resumo]. Em Sociedade Brasileira de Psicologia do Desenvolvimento (Org.), Resumos de comunicações científicas. IV Congresso Brasileiro de Psicologia do Desenvolvimento: contextos de desenvolvimento, educação e cultura (p. 245). João Pessoa: SBPD.

Snow, C. E. (1999) Social perspectives on the emergence of language. Em B. MacWhinney (Ed.), The emergence of Language (pp. 257273). Mahwah: Lawrence Erlbaum Associates.
Striano, T., \& Bertin, E. (2005). Social-cognitive skills between 5 and 10 months of age. Britsh Journal of Development Psychology, 23, $1-11$.

Striano, T., \& Reid, V. M. (2006). Social cognition in the first year. Trend in Cognitive Sciences, 10(10), 471-476.

Striano, T., \& Vaish, A. (2006). Seven-to-9-month-old infants use facial expression to interpret others' actions. British Journal of Developmental Psychology 24, 753-760.

Tomasello, M., \& Todd, J. (1983). Joint attention and lexical acquisition style. First Language, 4, 197-212.

Tomasello, M. (1995). Joint attention as social cognition. In C. Moore \& P. J. Dunham (Eds.), Joint attention: Its origins and role in development (pp. 103-130). Hillsdale, N J: Lawrence Erlbaum Associates.

Tomasello, M. (1999). The human adaptation for culture. Annual Reviews Anthropology, 28, 509-529.

Tomasello, M. (2000). Primate cognition: introduction to the issue. Cognitive Science, 24(3), 351-361.

Tomasello, M. (2003). Origens culturais da aquisição do conhecimento humano. (C. Berliner, Trad.). São Paulo: Martins Fontes (Coleção Tópicos).

Tomasello, M.; Carpenter, M., Call, J.; Behne, T., \& Moll, H. (2005). Understanding and sharing intentions: The origins of cultural cognition. Behavioral and Brain Sciences, 28, 5, 01-42.

Vygotsky, L. S. (2000). A Formação social da mente: $O$ desenvolvimento dos processos psicológicos superiores. (J. C. Neto, L. S. M. Barreto, S. C. Afeche, Trad.). $6^{\text {a }}$ ed.- São Paulo: Editora Martins Fontes (Original publicado em 1984).

Recebido em 31/07/2007

Aceito em 11/08/2008

Endereço para correspondência : Fabíola de Sousa Braz Aquino. Rua Aragão e Melo, 15, Apto 108-A, Ed. Expedicionários I, Torre, Cep:58040100, João Pessoa-PB, Brasil. E-mail: fsbrazaquino@ gmail.com 